\title{
Comportamentos indisciplinados em sala de aula: o que professores e estudantes pensam e fazem
}

\author{
Unruly behaviors in the classroom: what teachers and students think and do
}

\author{
Ilário Wecker \\ Mestre em Psicologia \\ Universidade Católica de Brasília \\ Brasília, DF - Brasil \\ ilariowecker@yahoo.com
}

\author{
Alessandra Rocha de Albuquerque \\ Doutora em Psicologia \\ Universidade Católica de Brasília \\ Brasília, DF - Brasil \\ arocha@p.ucb.br
}

\begin{abstract}
Resumo: Comportamentos indisciplinados são comuns entre estudantes de escolas brasileiras e têm impacto na trajetória escolar destes. Este estudo identificou a compreensão de indisciplina por professores e estudantes de uma escola privada confessional do DF e verificou a ocorrência de comportamentos de professores e estudantes, relacionados à indisciplina, em sala de aula. Oito professores e quatro estudantes do Ensino Fundamental foram entrevistados e diretamente observados. Foi evidenciada a compreensão de indisciplina como um fenômeno multideterminado de violação às regras e o uso de estratégias reforçadoras para lidar com comportamentos indisciplinados. Foram observadas discrepâncias entre o que os professores e estudantes relataram fazer e o que fazem e a ocorrência de comportamentos indisciplinados pelos estudantes. Concluiu-se, a partir da compreensão multicausal do fenômeno, que o manejo desses comportamentos deve envolver diferentes atores no contexto escolar e familiar e não ser focado apenas no estudante.
\end{abstract}

Palavras chave: comportamento indisciplinado; indisciplina escolar; manejo da indisciplina.

Abstract: Unruly behaviors are common among students of Brazilian schools and have an impact on their school trajectory. This study identified the understanding of indiscipline by teachers and students at a private confessional school in Federal District and verified the occurrence of teachers' and students' behaviors related to indiscipline in the classroom. Eight teachers and four elementary school students were interviewed and directly observed. Results showed the comprehension of indiscipline as a multidetermined phenomenon of violation of rules and the use of reinforcing strategies by the teachers to deal with unruly behaviors. Discrepancies were observed between what teachers and students reported doing and what they do in the classroom. Students presented unruly behaviors during the classes' observation. From the multicausal understanding of the phenomenon, it was concluded that the management of these behaviors must involve different actors in the school and family context and not be focused only on the student.

Keywords: unruly behavior; school indiscipline; indiscipline management.

Cite como

(ABNT NBR 6023:2018)

WECKER, Ilário; ALBUQUERQUE, Alessandra Rocha. Comportamentos indisciplinados em sala de aula: o que professores e estudantes pensam e fazem. Dialogia, São Paulo, n. 40, p. 1-21, e19908, jan./abr. 2022. Disponível em: https://doi.org/10.5585/40.2022.19908.

American Psychological Association (APA)

Wecker, I., \& Albuquerque, A. R.. (2022, jan./abr.) Comportamentos indisciplinados em sala de aula: o que professores e estudantes pensam e fazem. Dialogia, São Paulo, 40, p. 1-21, e19908. https://doi.org/10.5585/40.2022.19908. 


\section{Introdução}

A indisciplina escolar costuma ser definida em oposição à disciplina (FRELLER, 2001; OLIVEIRA, J., 2002; OLIVEIRA, M. I., 2011; REGO, 1996; SILVA, N., 2004) a qual é conceituada como um conjunto de regras de conduta, voltado para a manutenção da ordem. Diferentes autores compreendem a indisciplina como um fenômeno complexo e multideterminado, de violação de normas ou regras, que envolve comportamentos verbais e/ou físicos (e.g., AQUINO, 2003; BARBOSA, 2009; GARCIA, 1999; OLIVEIRA, M. I., 2011; PARRAT-DAYAN, 2012; RODRIGUES 2015; SILVA, M., 2001; VELEZ; VEIGA, 2010), o qual deve ser analisado a partir do contexto cultural e geográfico específico no qual ocorre (MOURA; PRODÓCIMO, 2017; OLIVEIRA, M. I., 2011). Oliveira (2015) define quatro tipos de indisciplina escolar: curricular, social, regimentar e passiva. A indisciplina curricular está relacionada ao rompimento dos contratos pedagógicos e impede o desenvolvimento da dinâmica de sala e, consequentemente, o processo de ensino e aprendizagem. A indisciplina social se refere às condutas inadequadas no ambiente de sala de aula, como usar equipamentos eletrônicos e fazer brincadeiras. A indisciplina regimentar é definida como o rompimento das normas estabelecidas pela instituição escolar. Por fim, a indisciplina passiva é caracterizada pelo desinteresse e não realização das atividades propostas em sala de aula pelo estudante.

Dados da Organization for Economic Cooperation and Development (OECD, 2009) apontam que a indisciplina escolar está presente em diferentes países. O Brasil, contudo, apresenta média de indisciplina superior à de outros 66 países e também se destaca em relação ao percentual de professores que relatam problemas de indisciplina com seus alunos. Enquanto no Japão e Noruega apenas 15\% dos professores do Ensino Fundamental relatam problemas de indisciplina dos alunos em sala, no Brasil esse percentual é de 64\%. Adicionalmente, o Brasil é o país onde os professores gastam mais tempo de aula, entre $18 \%$ a $20 \%$, na manutenção da ordem, enquanto a média internacional é de 13\% (OECD, 2014, apud SILVA; MATOS, 2017).

Aquino (2011, 2016) realizou duas revisões da literatura brasileira a respeito da disciplina/indisciplina escolar. A primeira revisão (AQUINO, 2011) compreendeu o período de 27 anos, entre 1979 e 2006, e incluiu a produção na forma de livros, artigos, dissertações e teses. O autor identificou 146 produções, três-quartos destas concentradas nos últimos sete anos (2000 a 2006) do levantamento. A produção de trabalhos acadêmicos (88 dissertações e 14 teses) foi predominante, seguida de livros (31) e, por fim, de artigos (13). A análise da natureza das produções mostrou o predomínio de obras prático-descritivas e pouco analíticas ou híbridas (práticodescritivas e analíticas). Adicionalmente, foi observada uma multiplicidade conceitual e teórica das 
publicações. A segunda revisão (AQUINO, 2016) focalizou apenas artigos no período entre 1998 a 2015. Foram identificados 35 artigos, publicados em 24 diferentes periódicos, 20 destes publicados no período de 13 anos, compreendido entre 1998 e 2010 e, outros 15 artigos publicados no período de cinco anos, entre 2011 e 2013. O autor concluiu por um aumento do interesse no tema, todavia apontou a dispersão dos estudos, uma vez que dialogam pouco entre si e, ainda, poucas são as revistas e autores com mais de um artigo a respeito da temática da indisciplina escolar. Em outro estudo (CASTRO; RODRIGUES, 2016), cujo objetivo foi analisar as produções contemporâneas sobre indisciplina escolar, foram identificadas 25 dissertações e nenhuma tese no período entre 2009 a 2016. Dos 25 estudos levantados, 19 eram provenientes de pós-graduação stricto sensu em Educação e nove destes foram analisados por terem explorado, na avaliação dos autores, o tema da indisciplina de forma mais aprofundada. A partir da análise desses nove estudos, os autores concluíram que, de modo geral os mesmos "criticam as tentativas de naturalizar a indisciplina, compreendendo-a como uma deficiência de determinados estudantes" (CASTRO; RODRIGUES, 2016, p. 27).

Partindo das revisões citadas (AQUINO, 2011, 2016; CASTRO; RODRIGUES, 2016) foi feita uma consulta ao Portal de Periódicos Capes, no período entre 2016 a 2020, para identificar artigos em português, revisados pelos pares, a partir do descritor "indisciplina escolar". Foram localizados 69 artigos, 43 destes empíricos, com predomínio, entre esses, de avaliações indiretas dos comportamentos indisciplinados com o uso de entrevistas e questionários. A análise dos resumos e métodos dos artigos empíricos revelou que apenas um dos estudos foi desenvolvido em uma escola privada, todos os demais ocorreram em escolas públicas. Adicionalmente, dos artigos empíricos, 33 contaram com a participação de professores, 21 com estudantes, dez com os coordenadores e apenas um desses estudos teve a participação dos pais.

Constata-se, desta forma, que apesar da alta incidência da indisciplina escolar em escolas brasileiras, o número de pesquisas sobre o tema ainda é baixo e há lacunas na literatura. Poucas pesquisas foram realizadas em escolas privadas, envolveram os estudantes e realizaram observações diretas em sala de aula. O comportamento indisciplinado é um problema em si e, também, costuma ser acompanhado de outros problemas escolares, os quais têm importante impacto na rotina escolar com potenciais prejuízos para o estudante. Dificuldades nas relações professor/estudante, estudante/estudante, estudante/comunidade educativa; aumento dos índices de repetência e prejuízos no processo de ensino-aprendizagem são relatados como subprodutos de comportamentos indisciplinados (LAGOS; CENTURION, 2018; MARTINS, 2014; PARRATDAYAN, 2012; RODRIGUES; MARQUES; GOMES, 2015; SOUZA, 2013). Deste modo, a 
realização de mais pesquisas sobre o tema, em contextos diferentes dos habitualmente estudados, dada a importância de que variáveis culturais e geográficas sejam consideradas (MOURA; PRODÓCIMO, 2017; OLIVEIRA, 2011) é importante. Tais pesquisas podem contribuir com a compreensão do fenômeno e fornecer subsídios à comunidade escolar para lidar preventivamente e remediativamente com o problema.

O presente estudo, de natureza exploratória, teve por objetivo geral identificar a compreensão de indisciplina escolar, por professores e estudantes de uma escola privada confessional do Distrito Federal (DF) e verificar a ocorrência de comportamentos de professores e estudantes relacionados à indisciplina escolar. Quanto aos objetivos específicos, buscou: identificar as concepções dos professores e estudantes sobre comportamentos indisciplinados em sala de aula; verificar, sob a concepção de professores e estudantes, os fatores que levam a comportamentos indisciplinados em sala de aula; identificar estratégias de prevenção e manejo da indisciplina em sala de aula utilizadas por professores; identificar comportamentos indisciplinados dos estudantes e favorecedores da indisciplina, por professores, em sala de aula.

\section{Método}

\subsection{Participantes}

Participaram da pesquisa quatro estudantes (A1, A2, A3 e A4) e oito professores (P1, P2, P3, P4, P5, P6, P7 e P8) de uma turma de $7^{\circ}$ ano do Ensino Fundamental. A escolha pelo $7^{\circ}$. ano ocorreu pelo fato deste ter sido apontado pela escola como o ano que apresentava o maior número de ocorrências disciplinares (com base em registros no sistema acadêmico e equipe de assistência de alunos).

A escolha de uma turma específica do $7^{\circ}$. ano, bem como dos estudantes desta, foi definida por sorteio. A turma sorteada foi inicialmente dividida em dois grandes grupos, de alunos com baixo número de ocorrências disciplinares (entre 0 e 10) e de alunos com alto número de ocorrências disciplinares (igual ou superior 11). Definidos esses dois grupos, foram excluídos de ambos alunos que: a) estudavam na escola há menos de dois anos; b) tinham menos de 12 ou mais de 14 anos; c) apresentavam diagnóstico formal de transtornos com impactos comportamentais (e.g., Transtorno de Déficit de Atenção/Hiperatividade; Transtorno do Espectro Autista). Aplicados esses critérios, foram sorteados dois estudantes (A1 e A2) no grupo daqueles com baixo número de ocorrências disciplinares e outros dois (A3 e A4) no grupo com alto número de ocorrências. Os professores foram também selecionados por meio de sorteio sendo que, do total de 16 professores regentes, oito participaram do estudo. 


\subsection{Considerações éticas}

O projeto foi submetido e aprovado pelo Comitê de Ética em Pesquisa com humanos da Universidade Católica de Brasília, com protocolo 18151419.3.0000.0029.

\subsection{Local}

O estudo foi realizado em uma escola católica que atende estudantes da Educação Infantil, Ensino Fundamental I e II e Ensino Médio. A escola conta com três unidades, localizadas em áreas diferentes e independentes, cada qual destinada a um nível educacional. A unidade destinada ao Ensino Fundamental, na qual os participantes estudavam, está localizada na Asa Sul, bairro de Brasília com índice de desenvolvimento humano (IDH) de 0,953, considerado alto (OLIVEIRA et al., 2015).

Foram utilizadas duas salas da escola para a coleta de dados. Uma sala de aula, com aproximadamente $48 \mathrm{~m}^{2}$, com 40 carteiras dispostas em fila, quadro branco e mesa de professor posicionada à frente da sala, computador e um projetor. Uma sala de atendimento individual, com aproximadamente $40 \mathrm{~m}^{2}$, contendo uma mesa e dez cadeiras.

\subsection{Instrumentos}

Foram utilizados os seguintes instrumentos na coleta de dados: protocolos de observação e roteiros de entrevistas semiestruturadas em versões diferentes para os professores e estudantes. Os roteiros de entrevista eram compostos por 24 questões, organizadas a partir de três eixos temáticos: a) conceito de indisciplina; b) fatores que contribuem para a indisciplina no contexto escolar e em sala de aula e c) estratégias utilizadas para minimizar comportamentos indisciplinados no contexto escolar e em sala de aula.

Os protocolos de observação foram adaptados do estudo de Lopes (2012). O protocolo de observação dos comportamentos dos estudantes era composto por sete classes comportamentais, cada uma delas formada por um conjunto de três a dez comportamentos, a saber: a) distrações e brincadeiras; b) deslocamentos; c) convenções sociais; d) sons e ruídos; e) atividades em sala de aula; f) processos relacionais aluno/aluno; g) processos relacionais professor/aluno. O protocolo de observação dos comportamentos dos professores continha cinco classes comportamentais, cada qual composta por quatro a seis comportamentos, a saber: a) deslocamentos e movimentos; b) regras e rotinas; c) barulho; d) trabalho; e) relação professor/aluno. 


\subsection{Procedimento}

Inicialmente foram realizadas as entrevistas individuais com os participantes, no contraturno das aulas, com base no roteiro de entrevista. Estas tiveram duração aproximada de 50 minutos.

Posteriormente, foram feitas observações diretas dos comportamentos dos participantes em sala de aula e registros por amostragem por tempo (DANNA; MATOS, 2006) dos comportamentos destes com uso dos protocolos de observação. Cada participante foi observado por 30 minutos, em dias e horários agendados de acordo com a conveniência destes e da escola. As observações e entrevistas foram integralmente gravadas em vídeo e áudio, respectivamente.

\section{Resultados}

Foram gerados dois conjuntos de dados: a) relatos verbais dos participantes, obtidos por meio de entrevistas; b) frequências dos comportamentos dos participantes em sala de aula, levantados por observação direta. Os dados das entrevistas foram analisados qualitativa e quantitativamente com o auxílio do programa Interface de $\mathrm{R}$ pour les Analvses Multidimensionnelles de Textes et de Questionnaires - IRaMuTeQ R (RATINAUD, 2009). Os dados das observações diretas foram analisados quantitativamente. Para assegurar a confiabilidade dos dados, um observador independente assistiu às gravações em vídeo de todas as observações realizadas em sala e preencheu os protocolos de observação, os quais foram comparados com aqueles preenchidos em sala de aula, de modo a calcular a fidedignidade entre observadores. $\mathrm{O}$ índice médio de fidedignidade foi de $93,1 \%$, com variação entre $71,42 \%$ a $100 \%$.

Os dados textuais das entrevistas foram organizados, separadamente, em dois diferentes corpus, um para os professores e outro para os estudantes, para fins de análise pelo software IRaMuTeQ R. Em ambos os casos, foram identificadas três classes pelo software, distribuídas em dois eixos principais: a) conceito de indisciplina; b) fatores relacionados à ocorrência de indisciplina escolar; c) estratégias de enfrentamento da indisciplina escolar. A partir da organização gráfica dos dados textuais em dendrogramas (SOUZA et al., 2018), apresentados nas Figuras 1 e 2, e das transcrições das entrevistas, o material textual foi interpretado.

A Figura 1 apresenta os dados dos professores. A classe conceito de indisciplina, corresponde a 29,7\% do material textual analisado; nesta classe foram incluídas palavras como atividade, conversa, brincadeira e atrapalhar, as quais evidenciam a ocorrência de comportamentos diferentes daqueles que costumam ser esperados em sala de aula (e.g., prestar atenção, fazer as tarefas) e que se afastam das normas sociais estabelecidas pela escola e dos contratos didáticos firmados entre 
docentes e discentes, conforme fica evidente na fala de alguns professores: "é um comportamento que foge dos contratos didáticos, ou seja, tudo aquilo que foge do que foi combinado no contrato didático e dos objetivos da aula e pelo professor" (P5); "é algum comportamento que transgride, que fere uma postura que a gente acha que seja adequada para um aluno dentro da sala de aula, para que ele possa ter um maior aproveitamento do processo de ensino aprendizagem" (P8). De um modo geral, ao conceituarem indisciplina, os professores fizeram referência exclusiva à forma de se comportar dos estudantes; apenas P1 e P2 relacionaram a indisciplina com a sua atuação em sala de aula: "algo que atrapalha a aprendizagem, variando de acordo com o objetivo da aula e da metodologia que vai ser usada para dinamizar o processo do ensino e aprendizagem” (P1).

Figura 1 - Conceito, fatores e estratégias de manejo da indisciplina escolar pelos professores

\begin{tabular}{|c|c|c|}
\hline Classe 3 & Classe 2 & Classe 1 \\
\hline $\begin{array}{l}\text { Conceito de indisciplina } \\
\qquad 29,7 \%\end{array}$ & $\begin{array}{c}\text { Fatores relacionados à } \\
\text { ocorrência de indisciplina } \\
\text { escolar } \\
45,8 \%\end{array}$ & $\begin{array}{l}\text { Estratégias de manejo da } \\
\text { indisciplina escolar } \\
24,5 \%\end{array}$ \\
\hline $\begin{array}{l}\text { conceito } \\
\text { atividade } \\
\text { conversa } \\
\text { ocorrer } \\
\text { dificultar } \\
\text { atitude } \\
\text { relacionar } \\
\text { referir } \\
\text { identificado } \\
\text { comportamento } \\
\text { ligar } \\
\text { conseguir } \\
\text { consequência } \\
\text { brincadeira } \\
\text { sala } \\
\text { baixo } \\
\text { aprendizagem } \\
\text { atrapalhar }\end{array}$ & $\begin{array}{l}\text { causador } \\
\text { contribuir } \\
\text { violar } \\
\text { falta } \\
\text { fator } \\
\text { familiar } \\
\text { questão } \\
\text { estudante } \\
\text { estabelecido } \\
\text { considerar } \\
\text { característica } \\
\text { regra } \\
\text { instituição } \\
\text { ausência } \\
\text { observar } \\
\text { norma } \\
\text { pai }\end{array}$ & $\begin{array}{l}\text { reduzir } \\
\text { açãoo } \\
\text { medida } \\
\text { conter } \\
\text { prevenir } \\
\text { sugestão } \\
\text { metodológico } \\
\text { direção } \\
\text { estratégia } \\
\text { indisciplina } \\
\text { usado } \\
\text { utilizar } \\
\text { comportamental } \\
\text { punição } \\
\text { unidade } \\
\text { aproximar } \\
\text { nriontarãn }\end{array}$ \\
\hline
\end{tabular}

Fonte: Autores.

A classe fatores relacionados a ocorrências de indisciplina agrupou o maior percentual de material textual analisado (45,8\%). Dentre as palavras destacadas, três delas (familiar, estudantes e instituição) indicam a compreensão da indisciplina escolar como um fenômeno afetado por diferentes variáveis. No que se refere à influência da instituição escolar nos comportamentos indisciplinados, P3 e P4 apontaram: "não cobrar as normas e regras, não deixar claro as normas e regras" (P3); "a postura da instituição, não entender as famílias, não ver o lado do professor, não 
ver o lado dos estudantes" (P4). Quanto à influência de fatores familiares, P1 afirmou: "falta de acompanhamento familiar, falta do amparo da família, não fazer parte da vida do estudante, falta do diálogo, falta de orientação, não ver, não dar atenção ao filho, não participar da vida acadêmica" (P1). Ao apontarem variáveis relacionadas aos estudantes, os professores destacaram o não cumprimento das normas e regras que são estabelecidas pela instituição ou o não cumprimento dos contratos didáticos estabelecidos pelos professores com a turma, ou seja, "não seguir os combinados que o professor tem com a turma, transgredir o que foi acordado com todos" (P4).

Em relação à classe estratégias de manejo da indisciplina escolar, que reuniu $24,5 \%$ do material textual, as palavras destacadas foram: reduzir, medidas, conter, prevenir, sugestão, direção, utilizar, punição, unidade, aproximar e orientação. Os relatos de P1 e P8 indicam alternativas usadas pelos professores para lidar com o problema da indisciplina: "sempre busco dialogar sobre os combinados, retomar sobre os cuidados que precisamos ter, orientar bem os estudantes, tratar com igualdade, sinalizo as medidas disciplinares" (P1); "eu uso a empatia, procurando me aproximar do aluno, me colocar no lugar dele, fazer com que o aluno me enxergue não só como um professor, mas como alguém que está muito próximo dele" (P8). As estratégias descritas por P1 e P8 se assemelham às da maioria dos professores, os quais enfocaram o uso de medidas não coercitivas e de diálogo para lidar com a indisciplina. Contudo, dois dos professores (P4 e P6) relataram a exploração de recursos didáticos para lidar com a indisciplina: "uso o mapa de sala, métodos didáticos exitosos, andar pela sala" (P4); "seriedade no planejamento, não dar folga para os estudantes, mostrar que você está com eles" (P6).

A Figura 2 apresenta os dados dos estudantes. A classe conceito de indisciplina agrupou 22,5\% do material textual analisado; nela destacam-se as palavras: conceito, atitude, posturas, falar, errado, correr, atrapalhar, respeitar e inadequado. Alguns trechos das entrevistas onde tais palavras aparecem como exemplos de indisciplina, de modo geral, como o descumprimento das regras institucionais, são apresentados a seguir: "os estudantes não obedecerem às regras e normas que são estabelecidas" (A1); “os estudantes não respeitarem as regras” (A2); “os estudantes não seguirem as regras" (A3) e "os estudantes quebrarem as regras e normas, atrapalhando aula, conversando, mascando chiclete, jogando bolinhas de papel” (A4). 
Figura 2 - Conceito, fatores e estratégias de manejo da indisciplina escolar pelos estudantes

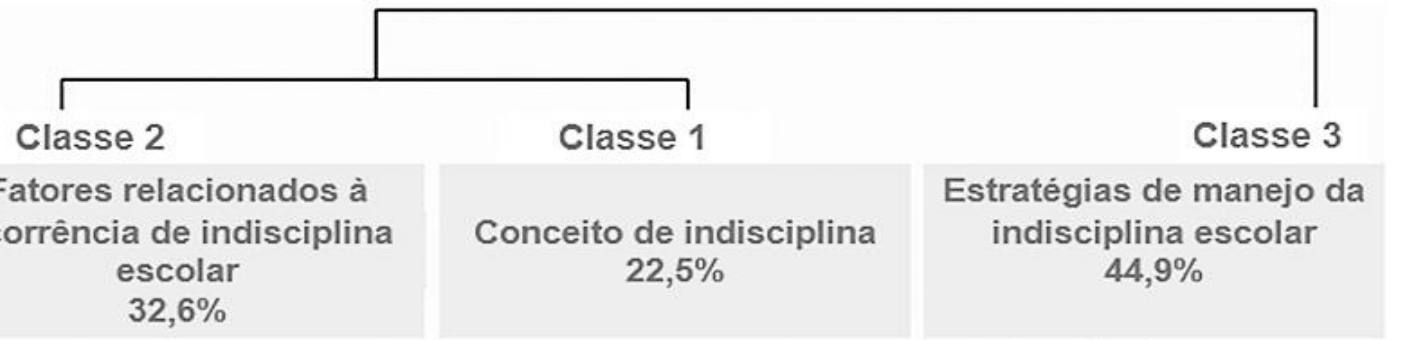

fator
escolar
ambiente
causador
violar
indisciplina
considerar
conversa
regra
brincadeira
celular
ocorrer
brincar
ficar
mexer
desrespeito
ver
acreditar
sala

conceito
coisa
atitude
postura
falar
errado
ocorrer
praticar
atrapalhar
respeitar
parar
inadequado
mexer
vez
desrespeito
professor
conversar
brincadeira

estratégia
aluno
conter
adotado
escola
diminuir
melhor
assistência
suspensão
utilizar
processo
sugerir
disciplinar
adequado
mandar
bom
retirar
perder

Fonte: Autores.

A classe fatores relacionados a ocorrências de indisciplina concentrou 32,6\% do conteúdo textual, com destaque para as seguintes palavras: fator, escolar, ambiente, causador, violar e indisciplina. As falas dos estudantes, transcritas a seguir, apontaram que estes se dividem quanto aos fatores que podem favorecer a indisciplina em sala de aula. Dois participantes (A1 e A2) apresentaram uma compreensão multideterminada da indisciplina e indicaram que tanto os professores, estudantes e a instituição escolar podem favorecer a ocorrência de comportamentos indisciplinados, conforme relatou A1: "nossa professora ela brinca de vez em quando na sala, aí teve uma amiga, ela gravou para brincar né, ela estava gravando aí a professora acabou tirando ela da sala. Os estudantes também podem influenciar os outros a não prestar a atenção, atrapalhar. A escola também pode influenciar, pois é na escola que os alunos se encontram e formam grupos, mas não sei bem se ela é ou não”. Os outros dois participantes atribuíram a indisciplina apenas ao próprio estudante ou a ele e aos professores, conforme relataram A4 e A3, respectivamente: "Os estudantes podem favorecer a indisciplina no contexto escolar e em sala"; "os professores podem favorecer comportamentos indisciplinados, pois, às vezes, gostam de brincar, falam palavrões no meio da aula ou ficam muito bravos, isso pode influenciar os alunos a fazer o mesmo. Já os estudantes também podem favorecer a indisciplina, como gritar na aula, conversar, mexer no celular"'. 
$\mathrm{Na}$ classe estratégias de manejo da indisciplina escolar foram agrupadas 44,9\% das informações textuais decorrentes das entrevistas. Dentre as 18 palavras agrupadas nessa classe, estão: estratégias, conter, adotar, diminuir, melhor, assistência, suspensão, sugerir, mandar e retirar. As respostas dos participantes indicaram estratégias que estes utilizam, que consideram eficazes, ou que poderiam ser adotadas por todos os estudantes: "fazer silêncio na da sala, acho que já ajuda" (A1); "chamar a atenção de quem estiver conversando, pedir para prestar atenção ou ajudar eles com os estudos" (A2); "prestar atenção, não conversar, não gritar em sala" (A3) e "busco dar exemplos, porque influencia os alunos, boas amizades, estudar, não falar palavrão" (A4).

Os comportamentos de professores e estudantes em sala de aula, analisados quantitativamente, são apresentados nos Gráficos 1 e 2. No Gráfico 1, referente aos professores, são apresentados os números de ocorrências (eixo y) das classes comportamentais observadas (eixo x) em sala de aula para cada participante (P1 a P8). Os comportamentos dos professores se concentraram em duas classes (regras e rotinas e trabalho), com poucas ocorrências de comportamentos das demais classes.

Gráfico 1 - Número de ocorrências dos comportamentos dos professores observados em sala por classe comportamental

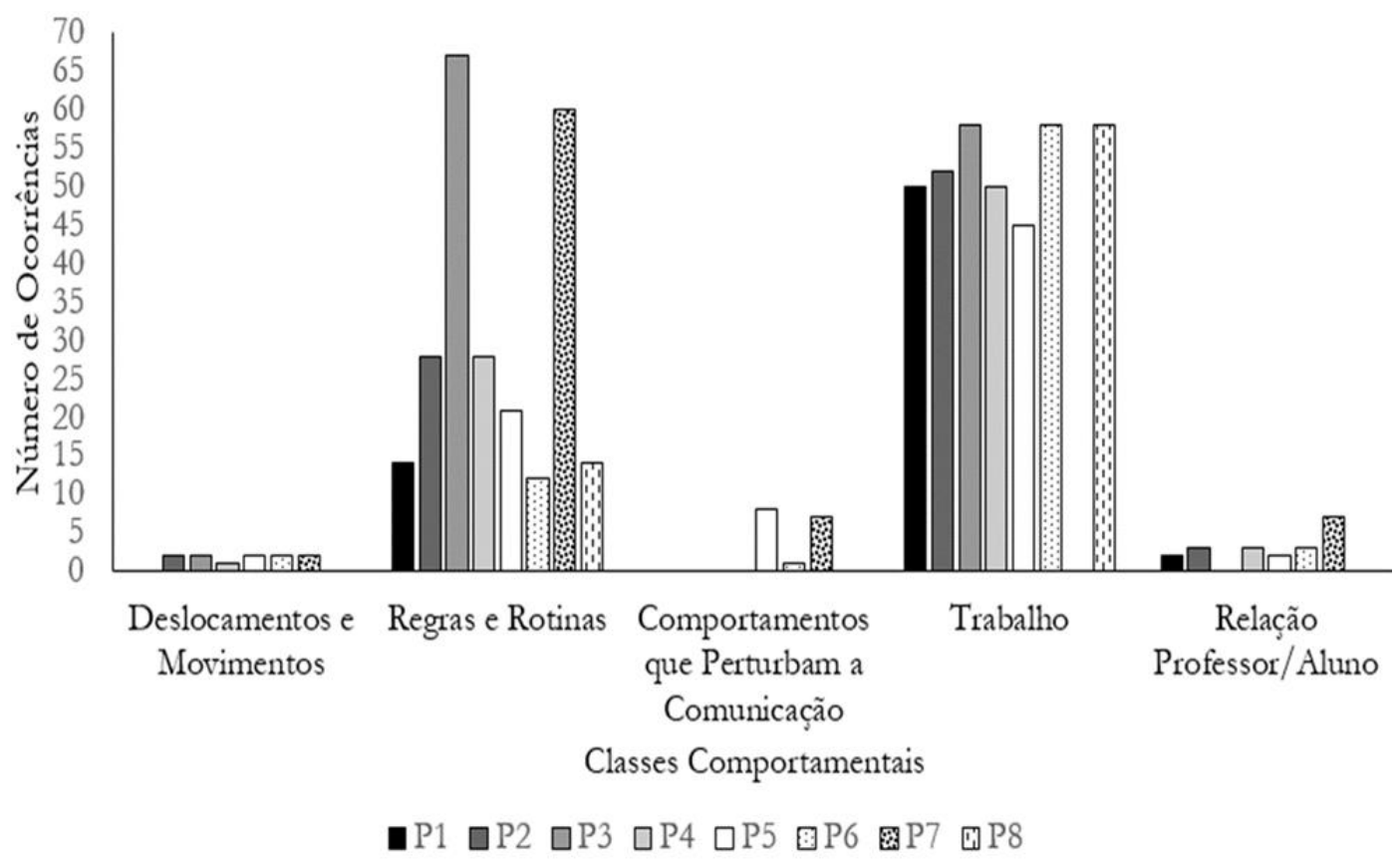

Fonte: Autores.

$\mathrm{Na}$ classe regras e rotinas (composta pelos comportamentos chegar atrasado, chamar atenção do aluno sem fazer referência às regras estabelecidas, aplicar as consequências pré-determinadas 
pelas regras estabelecidas de forma inconsistente e maus comportamentos dos alunos que não são consequenciados) dois comportamentos foram apresentados por todos os professores: chamar atenção dos alunos sem fazer referências às regras estabelecidas e maus comportamentos dos alunos não são consequenciados. $\mathrm{Na}$ classe trabalho (composta pelos comportamentos usar os mesmos métodos de ensino, desenvolver uma mesma atividade sem intercalar com outras, encerrar uma atividades sem que ela tenha sido concluída por falta de tempo, iniciar uma tarefa sem que tenha havido tempo para terminar as outras, iniciar uma atividade sem que haja tempo para as concluir e deixar tarefas por concluir), os comportamentos usar os mesmos métodos de ensino e desenvolver uma mesma atividade sem intercalar com outras, foram emitidos por todos os professores.

Os comportamentos dos estudantes são apresentados no Gráfico 2, que mostra o número de ocorrências (eixo x) dos comportamentos de cada classe comportamental, por participante (eixo y). As classes comportamentos que impedem as tarefas escolares e processos relacionais professor/aluno, apresentaram frequência nula para todos os estudantes. O maior número de ocorrências de comportamentos indisciplinados ocorreu na classe distrações/brincadeiras, composta por sete comportamentos (brincar em sala de aula com os materiais, brincar com os colegas, rir propositalmente, fazer algo para os outros rirem, fazer careta e bagunça, olhar para eventos/objetos não relacionados à aula e falar com os colegas). Nesta classe, o comportamento brincar em sala de aula com os materiais foi apresentado por todos os estudantes.

Gráfico 2 - Número de ocorrência dos comportamentos observados dos estudantes por classe comportamental

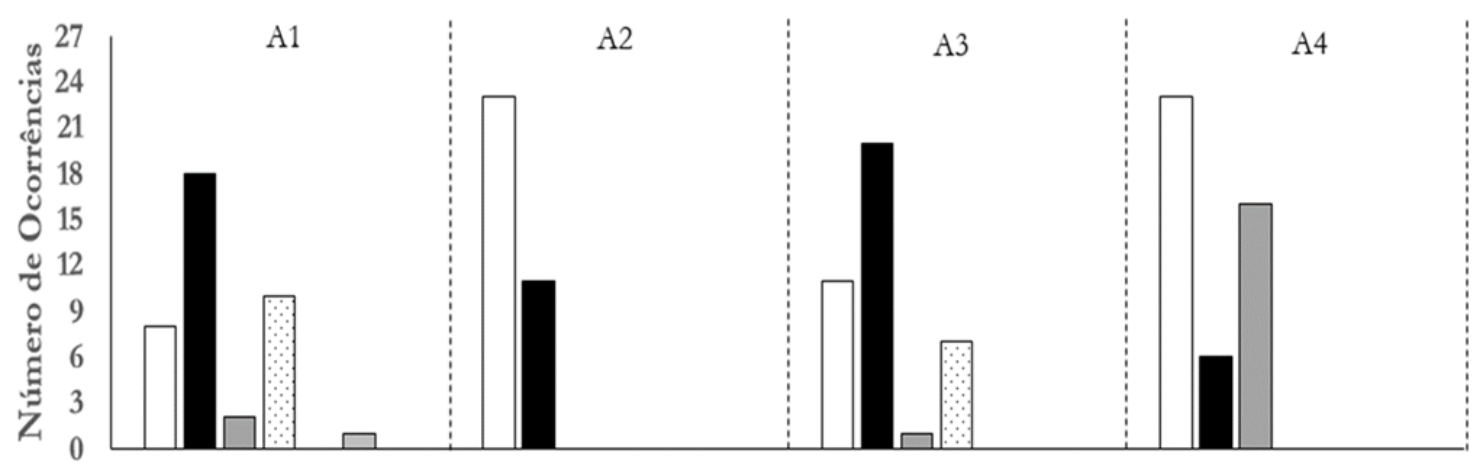

Classes

Comportamentais

$\square$ Distrações e Brincadeiras

๑Violação de Hábitos Sociais

目 Comportamentos que Impedem as Tarefas Escolares $\square$ Processos Relacionais Aluno/Aluno $\boxplus$ Processos Relacionais Professor/Aluno

Fonte: Autores.

\section{Discussão}


Os dados indicam que professores e estudantes, em geral, definem a indisciplina escolar de modo semelhante e como violação de regras estabelecidas no contexto escolar (e.g., "é um comportamento que foge de tudo aquilo do que foi combinado no contrato didático" - P5; "quebrarem as regras e normas" - A4). Definições similares, por professores, estudantes, coordenadores e familiares, foram relatadas em investigações anteriores (e.g., MOURA; PRODÓCIMO, 2017; REZENDE, 2018; SIQUEIRA, 2017).

A concepção de indisciplina como ruptura de regras corresponde, também, ao conceito de indisciplina regimentar proposto por Oliveira (2015). Apesar desta ser a concepção predominante dos participantes, os mesmos forneceram exemplos de outras modalidades de indisciplina (OLIVEIRA, 2015) - curricular, social e passiva. Os participantes P7 (“é qualquer ato que seja contrário à ordem da aula") e A4 ("atrapalha aula fazendo alguma coisa errada, conversando, mascando chiclete, jogando bolinhas de papel") destacaram o caráter prejudicial da indisciplina no andamento da aula e no processo de ensino-aprendizagem, o que corresponde ao conceito de indisciplina curricular. O caráter passivo da indisciplina, que consiste no não envolvimento dos estudantes nas atividades pedagógicas propostas (OLIVEIRA, M. T., 2015), também foi relatado por alguns professores, mas não pelos estudantes, que exploraram o caráter "ativo" da indisciplina (e.g., brincar, conversar, desobedecer). Os professores P6 e P5 apontaram explicitamente os aspectos passivos ao afirmarem que a indisciplina consiste em: "fugir do foco que está acontecendo na sala" (P6) e "não participar das aulas, não fazer a tarefa" (P5). A indisciplina social, caracterizada pela ruptura das regras sociais, foi exemplificada pelo participante P7 (“agressão física, agressão verbal, bullying").

É comum, no contexto do Ensino Fundamental, que contratos didáticos ou "combinados" sejam firmados. Deve-se considerar, contudo, que tais contratos constituem regras, como descrições verbais de comportamentos e suas consequências, as quais afetam diferencialmente o comportamento, se explícitas ou completas, a depender das consequências que estas descrevem e da convergência destas com as contingências das quais os comportamentos dos alunos fazem parte (ALBUQUERQUE; PARACAMPO, 2010). Os professores, contudo, disseram que nem sempre as regras são claras ou que são cumpridas por eles próprios. O professor P1, por exemplo, apontou a falta de clareza das regras como um dos fatores que favorecem a indisciplina ("não deixar claro as regras" - P1); P3, além de indicar a falta de clareza, chamou atenção para o fato dessas não serem cumpridas ("não cobrar as normas e regras, não deixar claro as normas e regras"). A incoerência entre regras e contingências foi identificada, também, por meio da observação direta dos comportamentos de professores e estudantes em sala de aula (Figuras 3 e 4) uma vez que todos 
os professores, em algum momento, não consequenciaram os comportamentos inadequados dos alunos e, mais, algumas vezes foi observado que o professor ameaçava o estudante, no sentido de chamar a atenção da consequência prevista para o seu comportamento, mas não cumpria a ameaça, ou seja, não consequenciava o comportamento do estudante da maneira prevista.

Para além dos fatores relacionados à clareza e coerência das regras, outros foram indicados como favorecedores da indisciplina por professores (Figura 1) e estudantes (Figura 2), os quais, de modo geral, atribuíram a indisciplina à sobreposição de diferentes fatores (família, escola, professores e estudantes), demonstrando uma compreensão multideterminada do fenômeno, a qual é coerente com a abordagem de diferentes estudos (e.g., AQUINO, 2003; BARBOSA, 2009; GARCIA, 1999; OLIVEIRA, M. I., 2011; PARRAT-DAYAN, 2012; RODRIGUES, 2015; SILVA, M., 2001; VELEZ; VEIGA, 2010). Neste sentido, os comportamentos indisciplinados podem ser compreendidos como parte integrante das contingências escolares e familiares. Com base na compreensão de contingência como uma unidade interativa, na qual há uma relação condicional entre eventos ambientais e comportamentais (TODOROV, 2012), comportamentos indisciplinados de estudantes interagem com diferentes contextos em um processo que envolve influências recíprocas (HÜBNER, 2012; PICADO, 2009).

Os professores indicaram o contexto familiar como um dos fatores que influenciam os comportamentos indisciplinados dos estudantes e destacaram a negligência familiar, a exemplo de P1 ("a falta de acompanhamento familiar, falta do amparo da família, não fazer parte da vida do estudante, falta do diálogo, falta de orientação, não ver o filho, não participar da vida acadêmica”) e P5 ("as famílias desestruturadas, família separada, pai e mãe que não exercem suas funções, ausência da família na escola, falta de relações afetivas, alcoolismo, drogas"). Resultado semelhante foi obtido por Silva, Negreiros e Albano (2016) em um estudo no qual 39\% dos professores atribuíram a indisciplina dos estudantes a alguma fragilidade familiar, como: falta de orientação, comportamentos ruins aprendidos no lar, ausência de regras claras, como as de papéis entre os membros da família, interferência de familiares próximos e também conflitos familiares.

Siqueira (2017), em estudo realizado com os estudantes, observou que 68\% dos entrevistados apontaram que os comportamentos indisciplinados/inadequados que são vivenciados na família, também são manifestados no ambiente escolar. No presente estudo, a família não foi elencada pelos estudantes como um dos fatores que favorecem a ocorrência de comportamentos indisciplinados na escola. A família, como o primeiro contexto social ao qual a criança é exposta e pelo impacto em diferentes aspectos do desenvolvimento humano, é um contexto social ímpar. Oliveira (2011) afirma que uma família onde pais e filhos se respeitam 
mutuamente, contribui para o equilíbrio emocional no lar e consequentemente melhora o comportamento e o desempenho acadêmico, social e escolar. Portanto, a família tem um papel importante a ser desempenhado na vida dos estudantes, na escola e na sociedade; os estudantes do presente estudo, contudo, não relacionaram a indisciplina escolar ao contexto familiar.

Além da família, os professores relataram que eles próprios, por meio de suas práticas pedagógicas, podem favorecer a indisciplina, a exemplo de P1 ("professor impaciente, professor intolerante, professor transmissor de conhecimento, professor que não se envolve com o estudante, professor que não dinamiza as aulas, professor que não cumpre com os combinados, professor que não orienta o estudante"). Os estudantes também citaram a influência dos professores nos comportamentos indisciplinados, segundo A2, "os professores podem favorecer comportamentos indisciplinados, principalmente quando o professor não entende o aluno". Outros estudos apresentaram dados semelhantes a estes (RENCA, 2008; SILVA; ABUD, 2016). Silva e Abud (2016) relataram que 60\% dos professores entrevistados relacionaram a indisciplina dos estudantes a seus próprios comportamentos e, no estudo de Renca (2008), os alunos responsabilizam os professores, por uma atuação deficiente, pela indisciplina em sala de aula. A dinamicidade e a qualidade dos processos de ensino desenvolvidos em sala são fatores importantes para garantir o interesse dos alunos, para a promoção da aprendizagem e para a qualidade das relações (MENDES, SANTOS; PAULA, 2012). Em muitas situações, os “professores exercem sua ação pedagógica sem a devida discussão com os alunos sobre suas expectativas e necessidades, podendo por meio destas atitudes causar indisciplina no contexto de sala de aula" (MENDES et al., 2012, p. 81).

Ao citarem o papel da instituição escolar na ocorrência de comportamentos indisciplinados, os professores novamente referiram-se à falta de clareza e flexibilização das normas e regras institucionais (e.g., "a instituição favorece quando ela não faz todos cumprirem as regras, não cobrar as regras, não deixar claro as normas e regras para todos, não fazerem os profissionais cobrarem as normas e regras" - P6). Para Boarini (2013, p. 128) o "comportamento indisciplinado pode estar revelando os conflitos velados da instituição e, mais que isso, pode estar indicando a insatisfação com uma escola, que dia a dia torna-se cada vez mais anacrônica e incompetente para cumprir sua função social”. Entre os estudantes, contudo, apenas um (A2) considera que a instituição escolar pode favorecer os comportamentos indisciplinados, porém, não explicita em que sentido.

Quanto às estratégias que são utilizadas para minimizar os comportamentos indisciplinados em sala de aula, foram observadas diferentes perspectivas entre professores e estudantes. $\mathrm{Na}$ 
perspectiva dos professores, foram identificados dois tipos fundamentais de estratégias: diálogo com os alunos e acolhimento (e.g., "relações afetivas com os estudantes, diálogo com os estudantes, se aproximar dos estudantes que estão sozinhos, passar confiança, legitimar o estudante, dar espaço para eles falarem, valorizar o estudante, elogiar a turma, motivar a turma” P5) e estratégias pedagógicas (e.g., "postura adequada do professor, aulas atrativas, ser pontual, dar exemplos, organizado, preparar bem os materiais" - P2). O diálogo e acolhimento explicitam a busca de uma relação afetiva com os estudantes; Aquino (1996, p. 50), ao tratar da indisciplina escolar, afirmou que "a saída possível está no coração mesmo da relação professor-aluno, isso é, nos nossos vínculos cotidianos e, principalmente, na maneira com que nos posicionamos perante o nosso outro complementar". O autor aponta ainda que "o lugar de professor é imediatamente relativo ao de aluno, e vice-versa. Vale lembrar que, guardada as especificidades das atribuições de agente e cliente, ambos são parceiros dos mesmos jogos" (AQUINO, 1996, p.50).

O foco em estratégias pedagógicas é coerente com a compreensão multidisciplinar apresentada pelos professores uma vez que estes, ao sugerirem que o uso de recursos pedagógicos alternativos, se implicam como parte do problema e da solução da indisciplina. Os professores foram também unânimes em rejeitar a suspensão ou expulsão de sala como estratégia válida de manejo da indisciplina. Deste modo, observa-se que as estratégias descritas pelos professores têm como base a prevenção ou enfraquecimento dos comportamentos indisciplinados dos estudantes por meio do uso de estratégias reforçadoras e não coercitivas. O reforço é uma ferramenta que pode favorecer os processos de ensino e aprendizagem e, ao mesmo tempo, facilitar as interações entre os estudantes e dos estudantes com os professores. Picado (2009, p. 5) "sublinha a importância da atuação do educador no comportamento do aluno, chama a atenção para o fato de que qualquer que seja a intervenção utilizada na sala de aula, a sua eficácia será limitada se não tiver em conta as necessidades individuais de cada aluno".

Os estudantes, contrariamente aos professores, quando questionados a respeito das estratégias de manejo da indisciplina, apontaram a suspensão e retirada de sala de aula como a estratégia mais eficaz (e.g., "eu acho que as suspensões...são a melhor maneira de diminuir comportamentos indisciplinados dos estudantes" - A1). Os participantes A1 e A4 consideram, ainda, que a retirada de sala de aula é a estratégia mais usada pelos professores ("mandar os alunos para a assistência, eu acho que é o que mais eles fazem" - A1; "primeiro é a assistência. Eles punem de acordo com o grau de indisciplina...ele vai ser suspenso... se ele leva muita suspensão ele vai ser expulso" - A4), o que contraria a fala dos professores. Esta contradição, contudo, é compreesível, pois a simples retirada de sala, apesar de não implicar na avaliação das variáveis que mantêm o 
comportamento indisciplinado dos estudantes e de ser uma estratégia coercitiva que não soluciona o problema a longo prazo, tem efeito imediato, uma vez que o professor "se livra" do problema. Viecili e Medeiros (2002, p. 230) afirmam que "a coerção se tornou uma das estratégias mais utilizadas em sala de aula, tendo em vista seus efeitos imediatos". "O uso da punição e da ameaça de punição para conseguir que outros ajam como nós gostaríamos ou a nossa prática de recompensar pessoas deixando-as escapar de nossas punições ou ameaças" (SIDMAN, 1995, p. 17) são formas de controle coercitivo do comportamento.

As estratégias que os estudantes relataram utilizar para manejo da indisciplina podem ser classificadas em três tipos: se comportar de modo disciplinado (e.g., "fazer silêncio na da sala, acho que já ajuda” - A1; "prestar atenção, não conversar, não gritar em sala" - A3); dar exemplo aos colegas (e.g., "busco dar exemplos, porque influência os alunos, boas amizades, estudar, não falar palavrão" - A4) e chamar atenção dos colegas (e.g., "chamar a atenção de quem estiver conversando, pedir para prestar atenção ou ajudar eles com os estudos” - A2).

Nas observações dos comportamentos dos professores e estudantes em sala de aula (Gráficos 1 e 2) ficaram evidentes discrepâncias entre o que os professores e estudantes relataram fazer e o que fazem. Os professores apresentam alguns comportamentos que podem favorecer a indisciplina por parte do estudante e que representam desvios das regras, explícitas ou implícitas, no contexto escolar (e.g., têm críticas relativas ao não cumprimento das regras, mas deixam de consequenciar comportamentos dos alunos de acordo com os "combinados" estabelecidos). No caso dos estudantes, ficou evidente que apesar de nenhum deles ter relatado que se considera indisciplinado, todos eles apresentaram comportamentos que se situam em pelo menos duas das classes comportamentais especificadas nesse estudo.

Portanto, nas observações, apesar do foco não ter recaído na interação professor-estudante, foram observados comportamentos dos professores que potencialmente podem favorecer a indisciplina das estudantes, seja por meio de exemplos inadequados aos processos pedagógicos, seja por meio de inconsistências entre as regras e contingências. No caso dos estudantes, foi interessante observar que aqueles tidos pela escola como mais indisciplinados (A3 e A4) não tiveram qualitativa e quantitativamente, comportamento muito diferentes dos menos indisciplinados (A1 e A2).

A partir da identificação das diferentes fontes ou origem dos comportamentos indisciplinados e de acordo com a perspectiva comportamental, que analisa o fenômeno como interação e como comportamento operante, Picado (2009, p. 5) destaca que "a identificação precisa dos comportamentos que desejamos alterar, constituem a primeira etapa do processo de mudança”. 
No entanto, a identificação dos comportamentos indisciplinados deve ocorrer de forma contextualizada e, não se pode observar apenas o indivíduo que se comporta de forma inadequada, mas devem ser observadas também as interações desse com o ambiente em que o mesmo está inserido: escola, professores, colegas, coordenação, meio social/familiar. É através de mudanças no ambiente que produzimos mudanças no comportamento e, do mesmo modo, na medida em que os comportamentos mudam eles afetam diferencialmente o ambiente. "Dessa maneira, se quisermos que nossas instituições mudem, sejam elas educacionais, governamentais ou industriais, precisamos mudar o comportamento dos indivíduos que as compõem” (DUPONT, 2007, p. 23).

\section{Considerações finais}

O presente estudo, de natureza descritiva, identificou o conceito, estratégias de manejo e variáveis que favorecem a indisciplina escolar na concepção de professores e estudantes de uma escola privada confessional do DF. Adicionalmente, avaliou a ocorrência de comportamentos indisciplinados de estudantes em sala de aula e de comportamentos de professores que podem favorecer a indisciplina escolar. A investigação realizada nesse contexto específico (escola privada), bem como o levantamento de informações sobre a indisciplina não apenas a partir do relato de professores e estudantes, mas também por meio da observação direta dos comportamentos dos mesmos, contribuem para a produção de conhecimento sobre um tema de extrema relevância no contexto escolar brasileiro, dada a sua alta incidência, seu impacto negativo na trajetória escolar de estudantes e, proporcionalmente a este impacto, um número pequeno de investigações.

Os dados permitem afirmar que os participantes conceituaram a indisciplina, predominantemente, como sendo uma violação de regras estabelecidas e como um fenômeno multideterminado, influenciado pelos contextos familiar e escolar, nesse último implicados os estudantes e professores. No que tange às estratégias de manejo da indisciplina em sala de aula, os professores relataram o uso de estratégias reforçadoras para lidar com o problema, todavia os estudantes consideraram que a retirada de sala de aula, aqui considerada uma estratégia coercitiva, é a estratégia mais usada pelos professores.

A observação direta dos comportamentos dos professores e estudantes em sala de aula agregou informações ao levantamento feito por meio das entrevistas. Considera-se, contudo, que apesar do longo tempo de observações em sala de aula, o tempo de observação individual de cada participante foi curto e os dados levantados podem revelar um recorte muito específico desse momento. Observações do comportamento de um mesmo aluno, em diferentes aulas, com diferentes professores podem agregar informações à compreensão do fenômeno da indisciplina. 
Ainda assim, esse estudo produz conhecimento e reflexões sobre o fenômeno da indisciplina, facilitando a compreensão do mesmo na perspectiva de professores e estudantes.

\section{Referências}

ALBUQUERQUE, Luiz Carlos de; PARACAMPO, Carla Cristina Paiva. Análise do controle por regras. Psicologia USP, São Paulo, v. 21, n. 2, p. 253-273, jun. 2010. DOI

https://doi.org/10.1590/S0103-65642010000200004. Disponível em:

https://www.scielo.br/j/pusp/a/qjdv4HdRkqCSZCq3PDFWQvq/?lang=pt. Acesso em: 1 jan. 2018.

AQUINO, Julio Groppa. A desordem na relação professor-aluno: indisciplina, moralidade e conhecimento. In: AQUINO, Julio Groppa. Indisciplina na escola: alternativas teóricas e práticas. São Paulo: Summus, v. 14, 1996. cap. 14, p. 39-55. ISBN 8532305830.

AQUINO, Julio Groppa. Indisciplina: o contraponto das escolas democráticas. São Paulo: Moderna, 2003. ISBN 85160390005.

AQUINO, Julio Groppa. Da (contra) normatividade do cotidiano escolar: problematizando discursos sobre a indisciplina discente. Cadernos de Pesquisa, v. 41, n. 143, p. 456-484, ago. 2011. DOI https://doi.org/10.1590/S0100-15742011000200007. Disponível em: https://www.scielo.br/j/cp/a/HMV47d5Wj5mWSt4P73jR7hj/?lang=pt. Acesso em: 1 jan. 2018.

AQUINO, Julio Groppa. Indisciplina escolar: um itinerário de um tema/problema de pesquisa. Cadernos de Pesquisa, São Paulo, v. 46, n. 161, p. 664-692, set. 2016. DOI https:/ / doi.org/10.1590/198053143670. Disponível em: https://www.scielo.br/j/cp/a/wXBYFtgdsnsRMxPfMSWDBXC/?lang=pt. Acesso em: 1 jan. 2018.

BARBOSA, Fernanda Aparecida Loiola. Indisciplina Escolar: diferentes Olhares Teóricos. In: IX Congresso Nacional de educação - EDUCERE e III Encontro Sul Brasileiro de Psicopedagogia-PUCPR. 2009. p. 4830-4840. Disponível em:

http://www.pucpr.br/eventos/educere/educere2009/anais/apresentacao.html

BOARINI, Maria Lucia. Indisciplina escolar: uma construção coletiva. Psicologia Escolar e Educacional, Maringá, v. 17, p. 123-131, jun. 2013. DOI https://doi.org/10.1590/S141385572013000100013. Disponível em:

https://www.scielo.br/j/pee/a/qThk57mv3vCvPxZBmwqC9cv/?lang=pt. Acesso em: 1 jan. 2018.

CASTRO, Camila Sandim; RODRIGUES, Luciana Azevedo. Disciplina e indisciplina escolar em tempos de sociedade excitada. Impulso, Piracicaba, v. 26, p. 23-37, 2016. DOI https://doi.org/10.15600/2236-9767/impulso.v26n67p23-37. Disponível em: https://www.metodista.br/revistas/revistas-unimep/index.php/impulso/article/view/2607. Acesso em: 1 jan. 2018.

DANNA, Marilda Fernandes; MATOS, Maria Amélia. Ensinando observaçäo: uma introduçäo. São Paulo: Edicon, 1996. 
DUPONT, Souzanne Langner. Análise do Livro “Coerção e Suas Implicações”, de M. Sidman (1995). 2007. Dissertação (Mestrado em Análise do Comportamento) - Universidade Estadual de Londrina, Londrina, 2007. f. 114.

FRELLER, Cintia Copit. Histórias de indisciplina escolar: o trabalho de um psicólogo numa perspectiva winnicottiana. São Paulo: Casa do Psicólogo, 2001. ISBN 9788573961300.

HÜBNER, Maria Martha. O Skinner que poucos conhecem: contribuições do autor para um mundo melhor, com ênfase na relação professor-aluno. In: CARMO, João dos Santos; RIBEIRO, Maria Julia Ferreira Xavier (Orgs.). Contribuições da análise do comportamento à prática. Santo André: ESETec Editores Associados, 2012, p. 73-85. ISBN 978-85-7918-043-9.

LAGOS, Marize; CENTURION, Diosnel. Impacto da indisciplina no processo de ensino do ensino fundamental de escolas públicas e particulares de Porto Velho-RO. Revista Cientifica da Faculdade de Educação e Meio Ambiente, Ariquemes, v. 9, n. 2, p. 668-678, 2018. DOI

https://doi.org/10.31072/rcf.v9i2.618. Disponível em: https://revista.faema.edu.br/index.php/Revista-FAEMA/article/view/618/614. Acesso em: 1 jan. 2018.

LOPES, Joana Brandão Araujo. Indisciplina em sala de aula: perspectivas de diferentes autores da comunidade escolar. 2012. 125 f. Dissertação (Mestrado em Psicologia da Educação) - Universidade dos Açores, Açores, 2012. f. 125.

MARTINS, Ernesto Candeias. Incumpridores versus indisciplinados no $1^{\circ}$ ciclo do ensino básico: estudo de caso de dois alunos duma escola urbana portuguesa. Interfaces da educação, Paranaíba, v. 5, n. 15, p. 165-187, 2014. Disponível em:

https://periodicosonline.uems.br/index.php/interfaces/article/view/453/419. Acesso em: 1 jan. 2018.

MENDES, Fabiane Mathias Delattre; SANTOS, Lucélia Gonçalves; PAULA, Veridyana Deitos. Um estudo sobre indisciplina e afetividade na escola. In: Seminário de Indisciplina na Educação Contemporânea. O Que Fažemos com as Mentes Rebeldes na Escola? 2012. p. 73-84. Disponível em: https://nipp.ufsc.br/files/2013/06/Anais-do-SIN-2012.pdf.

MOURA, Dirley Aparecido; PRODÓCIMO, Elaine. Indisciplina escolar na perspectiva de docentes e gestores de escolas estaduais de Indaiatuba/SP. Motrivivência, Florianópolis, v. 29, n. 51, p. 47-63, 2017. DOI https://doi.org/10.5007/2175-8042.2017v29n51p47. Disponível em: https://periodicos.ufsc.br/index.php/motrivivencia/article/view/2175-8042.2017v29n51p47. Acesso em: 1 jan. 2018.

OECD. Creating effective teaching and learning environments: First results from TALIS. Paris: OECD, 2009. 305 f. Acesso em 18 de novembro, 2018, de http://www.oecd.org/dataoecd/17/51/43023606.pdf.

OLIVEIRA, J. H. B. (In)Disciplina na sala de aula: perspectiva de alunos e professores. Psicologia, Educação e Cultura, Lisboa, v. 6, n. 1, p. 69-99, 2002.

OLIVEIRA, Maria Izete. Indisciplina escolar: determinantes, consequências e ações. Porto Alegre: Liber Livro Editora, 2011. ISBN 788598843155.

OLIVEIRA, Mariana Tavares Almeida. Conflitos entre alunos de 13 e 14 anos: causas, estratégias e finalizaçôes. 2015. Dissertação (Mestrado em Educação) - Faculdade de Educação, Universidade Estadual de Campinas, Campinas, 2015. f. 245. 
OLIVEIRA, Flávio Gonçalves; VALVERDE, Danielle Oliveira; ANDRADE, Keli Rodrigues; ROSA, Thiago Mendes. Vulnerabilidade, pobreza e a evolução do Índice de Desenvolvimento Humano Municipal (IDHM) nas Unidades de Desenvolvimento Humano (UDHs) do Distrito Federal. In: Programa das Nações Unidas para o Desenvolvimento, Instituto de Pesquisa Econômica Aplicada, Fundação João Pinheiro (Orgs.). Prêmio Atlas do Desenvolvimento Humano no Brasil: coletânea de artigos. Brasilia: PNDU, IPEA, FJP, 2015.

PARRAT-DAYAN, Silvia. Como enfrentar a indisciplina na escola. São Paulo: Contexto, 2012. ISBN 8572443932.

PICADO, L. A indisciplina em sala de aula: uma abordagem comportamental e cognitiva. Psicologia.com.pt. O portal dos psicólogos, 2009. Disponível em:

http://www.psicologia.pt/artigos/textos/A0484.pdf>.

RATINAUD, Pierre. IRaMuTeQ: Interface de R pour les Analyses Multidimensionnelles de Textes et de Questionnaires [Computer software], 2009. Disponível em: http://www.iramuteq.org,

REGO, Teresa Cristina R. A indisciplina e o processo educativo: uma análise na perspectiva vygotskyana. In: AQUINO, Julio Groppa (Org.). Indisciplina na escola: alternativas teóricas e práticas. São Paulo: Summus, 1996. p. 83-1-1. ISBN 8532305830.

RENCA, Antônio André. A indisciplina na sala de aula: percep̧õoes de alunos e professores. 2008. Dissertação (Mestrado em Análise Social e Administração da Educação) - Departamento de Ciência da Educação, Universidade de Aveiro, Aveiro, 2008. f.226.

REZENDE, Longuinha dos Santos. Gestão da indisciplina na escola de ensino fundamental: a percepção do professor sobre a indisciplina dos alunos. 2018. Dissertação (Mestrado em Docência e Gestão da Educação) - Universidade Fernando Pessoa, Porto, 2018. f. 133.

RODRIGUES, Icaro Arcênio de Alencar. A indisciplina e o regulamento disciplinar: Percepções de estudantes de cursos técnicos integrados. Revista Principia - Divulgação Científica e Tecnológica do IFPB, v. 1, n. 27, p. 89-95, 2015. DOI http://dx.doi.org/10.18265/1517-03062015v1n27p89-95. Disponível em: https://periodicos.ifpb.edu.br/index.php/principia/article/view/543. Acesso em: 1 jan. 2018.

RODRIGUES, Icaro Arcênio de Alencar; MARQUES, Larissa Carvalho; GOMES, Mácia Maria Costa. Como a indisciplina em sala de aula interfere no trabalho docente. Revista Principia -

Divulgação Científica e Tecnológica do IFPB, v. 1, n. 21, p. 21-29, 2015.

SIDMAN, Murray. Coerção e suas implicações. Santo André: Editorial Psy, 2003. ISBN 9788587622228.

SILVA, Maria Laura Fernandes. Indisciplina na aula: um problema dos nossos dias. Porto: Asa, 2001. ISBN 972-41-2056-2.

SILVA, Nelson Pedro. Ética, indisciplina \& violência nas escolas. Petrópolis: Vozes, 2004.

SILVA, Elisabeth Ramos; ABUD, Maria José Milharezi. As representações docentes sobre as causas da indisciplina na escola: de quem é a culpa. Revista do GEL, São Paulo, v. 13, n. 1, p. 87106, 2016. DOI https://doi.org/10.21165/gel.v13i1.548. Disponível em:

https://revistas.gel.org.br/rg/article/view/548. Acesso em: 1 jan. 2018. 
SILVA, Luciano Campos; MATOS, Daniel Abud Seabra. Indisciplina no Pisa: entre o intra e o extraescolar. Estudos em Avaliação Educacional, São Paulo, v. 28, n. 68, p. 382-416, ago. 2017. DOI http://dx.doi.org/10.18222/eae.v28i68.4590. Disponível em:

http://publicacoes.fcc.org.br//index.php/eae/article/view/4590. Acesso em: 1 jan. 2018.

SILVA, Algeless Milka Pereira Meireles; NEGREIROS, Fauston; ALBANO, Ronaldo Matos. Indiscipline at public school: teachers conceptions on causes and intervention. International Journal of Research in Education and Science, v. 3, n. 1, p. 1-10, nov. 2016. DOI

http://dx.doi.org/10.21890/ijres.267354. Disponível em: https://eric.ed.gov/?id=EJ1126690.

Acesso em: 1 jan. 2018.

SIQUEIRA, Mônica de Souza Carvalho. Indisciplina escolar: contribuições da família e da gestão escolar. 2017. Dissertação (Mestrado em Ciências da Educação) - Escola Superior de Educação Almeida Garrett, Lisboa, 2017. f. 273.

SOUZA, Flávio Fernando. Impactos da indisciplina no currículo: implicações para os contextos de ensino e aprendizagem. Horižntes, São Paulo, v. 31, n. 2, p. 39-47, dez. 2013. DOI https://doi.org/10.24933/horizontes.v31i2.5. Disponível em:

https://revistahorizontes.usf.edu.br/horizontes/article/view/5. Acesso em: 1 jan. 2018.

SOUZA, Marli Aparecida Rocha; WALL, Marilene Loewen; THULER, Andrea Cristina de Morais Chaves; LOWEN, Ingrid Margareth Voth; PERES, Aida Maris. O uso do software IRAMUTEQ na análise de dados em pesquisas qualitativas. Revista da Escola de Enfermagem da USP, São Paulo, v. 52, p. 1-7, 2018. DOI https://doi.org/10.1590/s1980-220x2017015003353. Disponível em: https://www.scielo.br/j/reeusp/a/pPCgsCCgX7t7mZWfp6QfCcC/?lang=pt. Acesso em: 1 jan. 2018.

TODOROV, João Claudio. O Conceito de contingência tríplice na análise do comportamento humano. Psicologia: Teoria e Pesquisa, v.1, n. 1, p. 75-88, 2012. Disponível em: https://periodicos.unb.br/index.php/revistaptp/article/view/16801. Acesso em: 1 jan. 2018.

VELEZ, Fernanda; VEIGA, Feliciano H. Indisciplina e violência na escola: distribuição dos alunos pela vitimização e pela agressão, por anos de escolaridade. In: Da exclusão à excelência: caminhos organizacionais para a qualidade da educaşão. Atas do XI Congresso da AEPEC, Évora, Portugal. 2010. p. 354-365. Disponível em: http://hdl.handle.net/10451/7034.

VIECILI, Juliane; MEDEIROS, José Gonçalves. A coerção e suas implicações na relação professor-aluno. Psico-USF, Itatiba, v. 7, n. 2, p. 229-238, dez. 2002. DOI https://doi.org/10.1590/S1413-82712002000200012. Disponível em: https://www.scielo.br/j/pusf/a/DvHMTfw9rvGRzwnFkH7npYm/?lang=pt. Acesso em: 1 jan. 2018. 